\title{
INTEGRATING TECHNOLOGY INTO HIGHER EDUCATION: A CASE STUDY IN LEBANON
}

\author{
Wael Hamzeh $^{1}$ (D), Khaleel Mershad ${ }^{1}$ (D), Sergey Vetohin ${ }^{2}(\mathbb{D})$ \\ ${ }^{1}$ Arts, Sciences and Technology University in Lebanon (Lebanon) \\ ${ }^{2}$ Belarusian State Technological University (Belarus) \\ wael.hamzeh@aul.edu.lb,kbaleel.mershad@aul.edu.lb,serega49@mail.ru
}

Received January 2019

Accepted May 2019

\section{Abstract}

The higher education sector in Lebanon has undergone significant changes in the past twenty years, with a rapid increase in the number of higher education institutions that differ greatly in their missions, methodologies, and regulations. One of the remarkable differences between higher education institutions (HEI) in Lebanon is their vision and adaptation of technology into their institutions, with the lack of any government rules that guide HEIs to proper technology implementation strategies. While some institutions use international standards and models for quality assurance and management as a base for technology integration, others implement their own strategies of choosing and applying the technologies they deem appropriate. In this paper, we study the effect of technology adaptation strategies on HEIs in Lebanon and propose a model for technology integration in higher education, based on the current needs and status of the Lebanese higher education system. We build our model on the goals of achieving and assuring high quality in the pedagogy, business, and technology sectors in the HEI.

Keywords - Higher education, Technology integration model, Quality assurance, Pedagogy quality, Business quality, Technology quality.

\section{To cite this article:}

Hamzeh, W., Mershad, K., \& Vetohin, S. (2019). Integrating technology into higher education: A case study in Lebanon. Journal of Technology and Science Education, 9(3), 442-457.

https://doi.org/10.3926/jotse.651

\section{Introduction}

The Lebanese Higher Education system is experiencing the effects of the dynamic environment in which it operates. Most of the 47 higher education institutions (HEI) currently in operation in Lebanon were legally established in the late nineties when the private education sector flourished in a sudden and rapid expansion following the 15-year civil war in Lebanon between 1975 and 1990 (Sphere, 2017). With the large number of private higher education institutions applying different educational systems, the Lebanese Higher Education System is definitely diverse, with the only state Lebanese University enjoying clear autonomy with its own system of governance.

The Lebanese Ministry of Higher Education has carefully been seeking to keep pace with the sector's development and seizing every opportunity to invite universities to establish policy mechanisms to ensure 
quality and accountability in higher education (Ghalayini \& El-Ghali, 2016). However, with the absence of a national QA agency whose standards for evaluation would be public and valid for all, each HEI is following a set of standards mostly in line with those of the external body that is intended to evaluate the institution (EACEA, 2017). Given all factors hindering the implementation of a complete law that would establish a national agency for quality assurance in higher education, a major concern remains nowadays on how Lebanese universities are implementing the quality assurance system internally.

When studying quality in higher education, a major element that steps to the front is the process of technology integration and its effect on the overall quality of the HEI. Ten years earlier, technology in education was a debatable topic amongst the society. Everyone had their own views on modernizing education and making it technology aided. As technology advanced, educational institutions everywhere realized the importance of technology in education, and how it improves education to a great extent and revolutionizes it for the better. Technology has now become an indispensable element in the educational process, and the quality of education is becoming more related to the quality of the used technology.

With the Lebanese higher education sector struggling to establish a clear standard for educational quality, each HEI continues to implement its own strategies in selecting and implementing the various technologies required for teaching and learning. With no clear results on the success or failure of various technology integration strategies that are being implemented by the Lebanese HEIs so far (we couldn't find any published documents by the Lebanese HEIs or MEHE that include such results), it remains a challenge to identify the effect of these strategies on the overall educational quality of the Lebanese HEIs. Moreover, various works in the literature (Ghalayini \& El-Ghali, 2016; Al-Alwani, 2014; Kaissi, Abou-Chahine \& Jammal, 2009) restricted the concept of quality assurance to its legal framework stressing the ultimate need for a law drafted by the Lebanese Ministry of Higher Education in order to preserve quality. To the best of our knowledge, no previous work considered the effect of correct technology adaptation and integration on the quality of higher education in Lebanon. This inference was reached after we performed a thorough review of all previous research on the quality of higher education in Lebanon and its various aspects and related factors.

In this paper, we aim at explaining and studying the importance of correct technology selection and integration on the quality of higher education in Lebanon. We pinpoint the decisive technology-related factors that play a role in improving or hindering the overall quality of the HEI. Towards these goals, we develop a model for correct technology integration within HEIs in Lebanon. The model is based on the current status of the Lebanese higher education sector and its relationship with the Lebanese and international business markets. Our model is built on top of three pillars: Pedagogy, Technology, and Business. Within each pillar, we define the technology-related factors that affect this part of the Lebanese higher education. Next, we deduce the corresponding Key Performance Indicators (KPIs) from these factors. The collection of deduced KPIs constitutes the basis of our model for technology integration with HEIs. In order to formalize our model, we performed a comprehensive survey covering five HEIs in Lebanon that were selected such that they have diverse educational systems (three main educational systems exist in Lebanon: Credit-based System, Course-based System, and Number of Years based System), styles (administration, admission rules, educational objectives, etc.), and background (years of experience, geographic span, number of branches and students, etc.). Our survey enabled us to define the weight of each KPI in each of the five HEIs and to calculate an average weight for each KPI in the proposed model. Based on the study, we discuss important results related to the current and future technology integration strategies within HEIs in Lebanon, and the efforts that are required to improve this process for a better educational quality in the Lebanese higher education.

The remaining of this paper is organized as follows: in the next section, we define the technology-related key factors that affect the quality of higher education in Lebanon. Next, we deduce the corresponding KPIs that constitute the basis of our proposed Technology Integration Model (TIM). After that, we illustrate how we conducted a comprehensive survey among several HEIs in order to complete and refine 
our proposed model. Finally, we discuss the lessons learned and the proposed recommendations for improving the process of technology integration.

\section{Design}

\subsection{Technology-Related Key Factors}

Integration of information technology is very important for modern educational systems as it acts as an effective tool for delivery of education to its users (Al-Alwani, 2014). Information technology has accelerated processes; broaden the scope and apt access to education. The usage of information technology systems and applications has gone through tremendous growth in the last decade to the extent that a high percentage of the success of an education system depends on the correct choice and implementation of the technology related to each part of the system.

Assessing the successful integration of information technology is a difficult task due to its complex nature as it involves the evaluation of direct and indirect variables (Al-Alwani, 2014). In this paper, we propose a model for proper technology integration into higher education. Our model can be used as a general guide for successful technology adaptation and integration in HEIs. In this paper, we make use of our model to study the current status of technology usage in the higher education sector in Lebanon, and the effect of the diversity of this sector on the different approaches that are taken by HEIs to implement various technologies, which affects the general quality of the institution. The obtained results help us to form an insight about the most effective technology adaption strategies that should be applied by HEIs in Lebanon. We also propose some recommendations for various Lebanese HEIs to improve the quality of higher education with effective technology integration based on the position and capabilities of the HEI.

First, we present the key factors that define the effect of technology on an HEI in general. We study this effect from three main perspectives: Pedagogy, Business, and Technology. From the first perspective, we outline the various criteria that affect the quality of teaching and learning. From the second perspective, we describe the criteria that play a role in improving or deteriorating the quality of the HEI financial operations, administration, and management. Finally, we present the criteria related to the choice of technology tools, software, and technology implementation strategies on the quality of the HEI. These criteria were deduced from a comprehensive literature study (in each of the three perspectives) that covered all important research works that address issues related to the quality of education in the three perspectives. For each of these three sections, we define a set of Key Factors (KFs) that will help us determine the KPIs of our proposed model. The complete description of the KFs is presented in a supplementary file in order to reduce the overall length of the paper.

\subsection{Key Performance Indicators (KPIs)}

The key factors that we presented in the previous section define the most important elements that play a role in the success or failure of the choice and integration of a new technology into any section in a HEI, resulting in an increase or decrease of the institution's quality in general, either on the short or the long time range. We divided these factors into three parts that are related to three main aspects of an HEI: Pedagogy, Business, and Technology. We can classify any factor that affects the technology integration process into one of these three sections, as we illustrated in the previous section.

After identifying the key factors that affect the technology integration process (TIP), we build our model by deducing the KPIs that can be used to measure the performance of the various actions that are related to the TIP. In this section, we present these KPIs. In the next section, we describe the process that we used to give a weight for each KPI in the model. In the following, we link each KPI to the key factor from which it was deduced using the following notion: $\mathrm{KPI}_{\mathrm{i}}$ : (Section- $\mathrm{KF}_{\mathrm{j}}$ ), where Section is $\mathrm{P}, \mathrm{B}$, or T; standing for Pedagogy, Business, and Technology respectively. For example, if we link $\mathrm{KPI}_{21}$ to $\mathrm{B}-\mathrm{KF}_{12}$, it means that $\mathrm{KPI}_{21}$ was deduced from key factor $\mathrm{KF}_{12}$ in the business section. 
The following is the list of KPIs that constitute our Technology Integration Model for higher education:

KPI 1 (P-KF 1 : The HEI adopts an efficient standard for defining learning outcomes for courses.

$\mathbf{K P I}_{2}\left(\mathrm{P}_{\mathrm{K}} \mathrm{KF}_{1}\right)$ : The HEI collaborates with business market experts to design the content of courses according to the business market needs.

$\mathbf{K P I}_{3}\left(\mathrm{P}-\mathrm{KF}_{1}\right)$ : The HEI takes into account students' feedback and recommendations regarding the curriculum content.

$\mathbf{K P I}_{4}\left(\mathrm{P}-\mathrm{KF}_{2}\right)$ : The HEI Instructors offer varieties of teaching methods that suit the learning needs of different students.

$\mathbf{K P I}_{5}\left(\mathrm{P}_{-} \mathrm{KF}_{2}\right)$ : The HEI instructors use different teaching tools that exploit various modern technologies.

KPI $\mathbf{I}_{6}\left(\mathrm{P}_{-}-\mathrm{KF}_{2}\right)$ : The HEI instructors know how to efficiently use active learning during lectures.

$\mathbf{K P I}_{7}\left(\mathrm{P}_{-}-\mathrm{KF}_{3}\right)$ : The HEI instructors know how to execute different teaching activities and strategies that are stated in $\mathrm{P}-\mathrm{KF}_{3}$.

$\mathbf{K P I}_{8}\left(\mathrm{P}_{-}-\mathrm{KF}_{4}\right)$ : The HEI instructors apply collaborative learning techniques during lectures, tutorials, labs, and assignments.

$\mathbf{K P I}_{9}\left(\mathrm{P}-\mathrm{KF}_{4}\right)$ : The HEI instructors monitor and test the collaborative learning process to ensure correct adoption and efficient outcomes.

$\mathbf{K P I}_{10}\left(\mathrm{P}-\mathrm{KF}_{5}\right)$ : Each instructor in the HEI knows his role in the overall mission of the HEI.

$\mathbf{K P I}_{11}\left(\mathrm{P}_{-}-\mathrm{KF}_{5}\right)$ : Each instructor knows the relationship between the materials he/she is teaching with the materials of other courses in the program.

$\mathbf{K P I}_{12}\left(\mathrm{P}_{-} \mathrm{KF}_{5}\right)$ : The HEI instructors know how to link the objectives and outcomes of their courses with the global objectives of the academic program.

$\mathbf{K P I}_{13}\left(\mathrm{P}-\mathrm{KF}_{5}\right)$ : The HEI instructors encourage students to learn and practice Interdisciplinary studies and activities.

$\mathbf{K P I}_{14}\left(\mathrm{P}-\mathrm{KF}_{6}\right)$ : The HEI encourages students to participate in quality-related committees and councils.

$\mathbf{K P I}_{15}\left(\mathrm{P}-\mathrm{KF}_{7}\right)$ : Each course includes the correct types of assessment that are suited for the type of material in the course (can be measured based on (O’Neill, 2011) and (Schwartz, 2012)).

$\mathbf{K P I}_{16}\left(\mathrm{P}_{-}-\mathrm{KF}_{7}\right)$ : The course assessments indicate clearly the extent to which the course learning outcomes have been achieved.

$\mathbf{K P I}_{17}\left(\mathrm{P}_{\left.-\mathrm{KF}_{7}\right)}\right.$ : The course assessments measure the knowledge, skills, and values outcomes related to the course material.

$\mathbf{K P I}_{18}\left(\mathrm{P}_{-} \mathrm{KF}_{7}\right)$ : The HEI instructors utilize technology-based assessment techniques, such as eportfolios.

$\mathbf{K P I}_{19}\left(\mathrm{P}-\mathrm{KF}_{8}\right)$ : The HEI instructors engage students in research activities within their courses.

$\mathbf{K P I}_{20}\left(\mathrm{P}_{-}-\mathrm{KF}_{8}\right)$ : The courses of each program in the HEI include a collection of research activities that can be divided among the four research categories (defined in $\mathrm{P}-\mathrm{KF}_{8}$ ).

$\mathbf{K P I}_{21}\left(\mathrm{P}_{-} \mathrm{KF}_{9}\right)$ : The HEI considers the teaching abilities and the practical skills of instructors as important factors in determining the instructor's rank.

$\mathbf{K P I}_{22}\left(\mathrm{P}_{-} \mathrm{KF}_{9}\right)$ : The HEI contains a Teaching Quality department that gives proper guidance and tools to instructors and monitors their teaching qualities. 
$\mathbf{K P I}_{23}\left(\mathrm{P}-\mathrm{KF}_{10}\right)$ : The HEI monitors the teaching skills of its instructors and helps them to improve their teaching abilities.

$\mathbf{K P I}_{24}\left(\mathrm{P}-\mathrm{KF}_{11}\right)$ : The HEI considers the factors stated in $\mathrm{P}-\mathrm{KF}_{11}$ when promoting an instructor.

$\mathbf{K P I}_{25}\left(\mathrm{P}-\mathrm{KF}_{12}\right)$ : The HEI encourages students to engage in the business society and the labor market.

$\mathbf{K P I}_{26}\left(\mathrm{P}-\mathrm{KF}_{13}\right)$ : The HEI provides the necessary funding to its instructors to participate in research projects and training courses.

$\mathbf{K P I}_{27}\left(\mathrm{P}-\mathrm{KF}_{13}\right)$ : The HEI instructors collaborate with fellows from national and international HEIs within exchange programs for students and faculty.

$\mathbf{K P I}_{28}\left(\mathrm{P}-\mathrm{KF}_{14}\right)$ : The HEI contains standards and recommendations for different methods of outside-classroom interactions between students and instructors.

$\mathbf{K P I}_{29}\left(\mathrm{P}-\mathrm{KF}_{15}\right)$ : The HEI administrators possess the abilities and qualifications to perceive the quality levels of their departments and sections and the possibilities for their improvement.

$\mathbf{K P I}_{30}\left(\mathrm{~B}-\mathrm{KF}_{1}\right)$ : The HEI has a mission statement with a clear set of objectives.

$\mathbf{K P I}_{31}\left(\mathrm{~B}-\mathrm{KF}_{1}\right)$ : The HEI periodically reviews the mission statement and implements strategies to calculate the percentage of completeness of each of its objectives.

$\mathbf{K P I}_{32}\left(\mathrm{~B}-\mathrm{KF}_{1}\right)$ : The HEI updates its mission statement at the end of each academic year based on changes in the higher education standards and requirements.

$\mathbf{K P I}_{33}\left(\mathrm{~B}-\mathrm{KF}_{2}\right)$ : The HEI maintains a profile of financial objectives that are created and updated based on standard models for higher education (such as (OECD, 2014) or (Lapovsky, 2013)).

$\mathbf{K P I}_{34}\left(\mathrm{~B}-\mathrm{KF}_{3}\right)$ : The HEI defines a list of educational objectives as part of its mission statement, and uses them to outline the learning outcomes for each course.

$\mathbf{K P I}_{35}\left(\mathrm{~B}-\mathrm{KF}_{3}\right)$ : The HEI adopts a mechanism for tracking students after graduation to monitor the success of achieving its defined learning outcomes.

$\mathbf{K P I}_{36}\left(\mathrm{~B}-\mathrm{KF}_{4}\right)$ : The HEI makes frequent meetings with industry and business representatives to monitor their students' performance and acquire information about changes and additions in the industry and business needs.

$\mathbf{K P I}_{37}\left(\mathrm{~B}-\mathrm{KF}_{4}\right)$ : The HEI provides internships and training to its students at high-quality companies, industries, and business institutions.

$\mathbf{K P I}_{38}\left(\mathrm{~B}-\mathrm{KF}_{4}\right)$ : The HEI offers training courses and workshops, employment seminars, and job fairs to its students.

$\mathbf{K P I}_{39}\left(\mathrm{~B}-\mathrm{KF}_{5}\right)$ : The HEI distributes the credit load efficiently for each major and specialization.

$\mathbf{K P I}_{40}\left(\mathrm{~B}-\mathrm{KF}_{5}\right)$ : The HEI requires a balanced load of credit hours, research work, and community services from its tenured faculty.

$\mathbf{K P I}_{41}\left(\mathrm{~B}-\mathrm{KF}_{5}\right)$ : The HEI follows a national benchmark in defining the salary of tenured faculty and the hour or credit salary of part-timers.

$\mathbf{K P I}_{42}\left(\mathrm{~B}-\mathrm{KF}_{5}\right)$ : The HEI follows a clear policy regarding the number of faculty positions, halftime positions (if adopted), and part-time positions based on the number of students in each program.

$\mathbf{K P I}_{43}\left(\mathrm{~B}-\mathrm{KF}_{5}\right)$ : The HEI follows a clear policy regarding the minimum number of students per course section.

$\mathbf{K P I}_{44}\left(\mathrm{~B}-\mathrm{KF}_{5}\right)$ : The HEI follows a clear policy regarding the minimum percentage of instructors with a Ph.D. degree in each program. 
$\mathbf{K P I}_{45}\left(\mathrm{~B}-\mathrm{KF}_{5}\right)$ : The HEI follows a clear policy regarding the maximum allowed number of semesters for each degree.

$\mathbf{K P I}_{46}\left(\mathrm{~B}-\mathrm{KF}_{6}\right)$ : The HEI conducts surveys and meetings with students and parents to discuss their recommendations and suggestions for improving the HEI services.

$\mathbf{K P I}_{47}\left(\mathrm{~B}-\mathrm{KF}_{6}\right)$ : The HEI offers transferrable credits to accommodate students who need to move in and out of the HEI.

$\mathbf{K P I}_{48}\left(\mathrm{~B}-\mathrm{KF}_{7}\right)$ : The HEI offers a variety of degrees and majors that cover a wide range of jobs.

$\mathbf{K P I}_{49}\left(\mathrm{~B}-\mathrm{KF}_{7}\right)$ : The HEI offers multidisciplinary majors that span multiple programs.

$\mathbf{K P I}_{50}\left(\mathrm{~B}-\mathrm{KF}_{7}\right)$ : The HEI offers postgraduate programs (Masters, Ph.D.) within its various faculties and departments.

$\mathbf{K P I}_{51}\left(\mathrm{~B}-\mathrm{KF}_{8}\right)$ : The HEI follows a precise strategy for admission, screening applications, and selecting students to various programs.

$\mathbf{K P I}_{52}\left(\mathrm{~B}-\mathrm{KF}_{8}\right)$ : The HEI conducts entrance exams that test the levels of candidate students according to the national standard requirements of each program.

$\mathbf{K P I}_{53}\left(\mathrm{~B}-\mathrm{KF}_{8}\right)$ : The HEI policies contain rules for students' probation and dismissal conditions.

$\mathbf{K P I}_{54}\left(\mathrm{~B}-\mathrm{KF}_{9}\right)$ : The HEI requires affordable fees that match the quality of various services that are offered by the HEI.

$\mathbf{K P I}_{55}\left(\mathrm{~B}-\mathrm{KF}_{9}\right)$ : The HEI offers financial aid, teaching assistantships, and scholarships to students.

$\mathbf{K P I}_{56}\left(\mathrm{~B}-\mathrm{KF}_{9}\right)$ : The HEI presents career advising information and help to students.

$\mathbf{K P I}_{57}\left(\mathrm{~B}-\mathrm{KF}_{10}\right)$ : The HEI requires a certain minimum of academic requirements (teaching experience, research achievements, and community service) of each new and continuing faculty member according to his/her academic rank.

$\mathbf{K P I}_{58}\left(\mathrm{~B}-\mathrm{KF}_{10}\right)$ : The HEI rewards and promotes successful faculty members.

$\mathbf{K P I}_{59}\left(\mathrm{~B}-\mathrm{KF}_{11}\right)$ : The students and parents are satisfied with the level of services that are offered by the HEI departments.

$\mathbf{K P I}_{60}\left(\mathrm{~B}-\mathrm{KF}_{11}\right)$ : The HEI contains one or more libraries that offer printed and electronic resources and services to students.

$\mathbf{K P I}_{61}\left(\mathrm{~B}-\mathrm{KF}_{11}\right)$ : The HEI provides necessary medical care for faculty, staff, and students.

$\mathbf{K P I}_{62}\left(\mathrm{~B}-\mathrm{KF}_{11}\right)$ : The HEI contains department(s) for various safety and security aspects.

$\mathbf{K P I}_{63}\left(\mathrm{~B}-\mathrm{KF}_{11}\right)$ : The HEI contains sports facilities, social clubs and communities, and transportation services.

$\mathbf{K P I}_{64}\left(\mathrm{~B}-\mathrm{KF}_{12}\right)$ : The HEI possesses and manages a professional website that can be used to obtain various services and information.

$\mathbf{K P I}_{65}\left(\mathrm{~B}-\mathrm{KF}_{13}\right)$ : The HEI identifies and implements decision-making rules that assign the different responsibilities of each individual and group.

$\mathbf{K P I}_{66}\left(\mathrm{~B}-\mathrm{KF}_{13}\right)$ : The HEI implements methods for monitoring the various decisions that are made at different administration and academic levels.

$\mathbf{K P I}_{67}\left(\mathrm{~B}-\mathrm{KF}_{14}\right)$ : The HEI contains a department for securing and managing various funding opportunities and support for faculty, staff, and students

$\mathbf{K P I}_{68}\left(\mathrm{~B}-\mathrm{KF}_{15}\right)$ : The HEI defines a list of quality preferences and follows a plan for achieving a certain level in each of the desired qualities as defined in the HEI mission statement. 
$\mathbf{K P I}_{69}\left(\mathrm{~B}-\mathrm{KF}_{15}\right)$ : The HEI compares its achieved and target quality levels with those defined by the government standards.

$\mathbf{K P I}_{70}\left(\mathrm{~B}-\mathrm{KF}_{15}\right)$ : The HEI follows a plan to make full use of its existing resources (human, assets, relationships), and a plan to acquire missing required resources.

$\mathbf{K P I}_{71}\left(\mathrm{~B}-\mathrm{KF}_{15}\right)$ : The HEI is environment preservative in all its activities, services, and regulations.

$\mathbf{K P I}_{72}\left(\mathrm{~B}-\mathrm{KF}_{16}\right)$ : The HEI contains an assessment committee that is responsible for evaluating the successfulness of the university mission at the end of each academic year.

$\mathbf{K P I}_{73}\left(\mathrm{~T}-\mathrm{KF}_{1}\right)$ : The HEI contains a committee or unit for educational technology-related matters.

$\mathbf{K P I}_{74}\left(\mathrm{~T}-\mathrm{KF}_{1}\right)$ : The educational technology unit searches and proposes new technologies that successfully enhance the quality of education at the HEI.

$\mathbf{K P I}_{75}\left(\mathrm{~T}-\mathrm{KF}_{2}\right)$ : The HEI utilizes dynamic educational techniques and dynamic content delivery within the HEI curricula.

$\mathbf{K P I}_{76}\left(\mathrm{~T}-\mathrm{KF}_{3}\right)$ : The HEI uses a powerful Learning Management System as part of its electronic system.

$\mathbf{K P I}_{77}\left(\mathrm{~T}^{-} \mathrm{KF}_{3}\right)$ : The HEI illustrates to its community (faculty, staff, and students) the various benefits obtained from using the LMS features.

$\mathbf{K P I}_{78}\left(\mathrm{~T}-\mathrm{KF}_{3}\right)$ : The HEI instructors make full use of the various features of the adopted LMS and record their lectures and upload them into the LMS.

$\mathbf{K P I}_{79}\left(\mathrm{~T}^{-} \mathrm{KF}_{3}\right)$ : The HEI employs specialized IT personnel who give help to instructors and students about various issues related to the LMS.

$\mathbf{K P I}_{80}\left(\mathrm{~T}^{-} \mathrm{KF}_{4}\right)$ : The HEI instructors have good knowledge about various Internet educational resources.

$\mathbf{K P I}_{81}\left(\mathrm{~T}-\mathrm{KF}_{4}\right)$ : The HEI provides adequate help to students in order to discover important Internet resources and make use of them.

$\mathbf{K P I}_{82}\left(\mathrm{~T}-\mathrm{KF}_{5}\right)$ : The HEI provides help to instructors in terms of suggesting technology tools and software that could be used in their courses.

$\mathbf{K P I}_{83}\left(\mathrm{~T}-\mathrm{KF}_{5}\right)$ : The HEI collects feedback from instructors on the results of using various technologies in their courses.

$\mathbf{K P I}_{84}\left(\mathrm{~T}_{-}-\mathrm{KF}_{5}\right)$ : The HEI cooperates with other similar institutions by sharing and discussing the results of implementing and adopting various technologies.

$\mathbf{K P I}_{85}\left(\mathrm{~T}-\mathrm{KF}_{6}\right)$ : The HEI encourages students to create their own knowledge experience by utilizing innovational technology tools and methods.

$\mathbf{K P I}_{86}\left(\mathrm{~T}_{-} \mathrm{KF}_{6}\right)$ : The HEI utilizes various technology tools that help students adjust their learning times according to their schedule priorities.

$\mathbf{K P I}_{87}\left(\mathrm{~T}-\mathrm{KF}_{6}\right)$ : The HEI adopts competency-based educational methods.

$\mathbf{K P I}_{88}\left(\mathrm{~T}-\mathrm{KF}_{6}\right)$ : The HEI integrates blended and mobile learning models in its curricula.

$\mathbf{K P I}_{89}\left(\mathrm{~T}-\mathrm{KF}_{7}\right)$ : The HEI contains regulations for helping students with disabilities achieve equal learning.

$\mathbf{K P I}_{\mathbf{9 0}_{0}}\left(\mathrm{~T}-\mathrm{KF}_{7}\right)$ : The HEI implements technology tools dedicated for helping students with disabilities.

$\mathbf{K P I}_{91}\left(\mathrm{~T}-\mathrm{KF}_{8}\right)$ : The HEI implements and tests technology tools that enable instructors to monitor the performance of each student and provide him with the necessary educational help. 
$\mathbf{K P I}_{92}\left(\mathrm{~T}_{-} \mathrm{KF}_{9}\right)$ : The HEI installs and updates modern educational technology tools in its various facilities.

$\mathbf{K P I}_{93}\left(\mathrm{~T}-\mathrm{KF}_{10}\right)$ : The HEI utilizes educational technology tools to modify the structure and content of courses with high failure rate.

$\mathbf{K P I}_{94}\left(\mathrm{~T}-\mathrm{KF}_{11}\right)$ : The HEI combines traditional assessment with authentic assessment methods.

$\mathbf{K P I}_{95}\left(\mathrm{~T}_{-} \mathrm{KF}_{12}\right)$ : The HEI provides technology-enhanced education at affordable costs.

$\mathbf{K P I}_{96}\left(\mathrm{~T}-\mathrm{KF}_{13}\right)$ : The HEI defines and implements a technology integration plan for integrating new technologies; and collects and analyzes feedback from the integration process.

$\mathbf{K P I}_{97}\left(\mathrm{~T}-\mathrm{KF}_{14}\right)$ : The HEI introduces students to the process of documenting what they are learning and provide them with the necessary tools for performing the documentation.

$\mathbf{K P I}_{98}\left(\mathrm{~T}-\mathrm{KF}_{15}\right)$ : The HEI encourages students to participate in online learning communities and supports them with the necessary collaboration tools.

$\mathbf{K P I}_{99}\left(\mathrm{~T}-\mathrm{KF}_{16}\right)$ : The HEI makes use of technology advances to increase physical and data security on the campus.

$\mathbf{K P I}_{100}\left(\mathrm{~T}-\mathrm{KF}_{17}\right)$ : The HEI defines policies for using technology tools as a means for communication between instructors and students.

\section{Approach: Technology Integration Model}

In the previous section, we stated the KPIs that constitute our proposed Technology Integration Model. Each of these KPIs affects the TIP to a certain extent. In this section, we quantify the degree to which each KPI has its effect on the TIP. In other words, we identify the weight that should be given to each KPI in the model. In order to calculate the weight of each KPI, we decided to seek the opinions of higher education experts and professionals in Lebanon. Hence, we conducted a comprehensive survey that covered 435 people who work as administrators, managers, faculty members, and instructors in eight universities in Lebanon. We chose the eight universities such that they cover the diverse characteristics of most HEIs in Lebanon. For example, we chose the Lebanese University since it is the only governmental HEI in Lebanon. We chose the American University of Beirut since it is among the highest ranked universities in Lebanon. We chose the Arts, Sciences, and Technology University (AUL) since it is one of the newer universities that are trying to improve their rank to compete with older and more experienced universities. We chose the Lebanese International University (LIU) since it spans over the widest geographical area (compared to other Lebanese universities) with its nine branches. The remaining chosen universities are: Beirut Arab University (BAU), Islamic University of Lebanon (IUL), Notre Dame University (NDU), and Phoenicia University (PU).

Among the 435 employees from the eight universities who participated in the survey, 190 (43\%) work as faculty members (assistant, associate, or full professors) and $125(29 \%)$ work as instructors (Lecturers, part-time professors, and research directors and associates). The participants from these two categories were chosen from various faculties and departments in the eight universities. Specifically, the 190 faculty members and 125 instructors span over 15 faculties and 42 departments. As for the other two categories, $60(14 \%)$ participants work as administrators (IT, finance, HR, admission, PR, etc.). These were chosen as sections heads and managers of certain non-academic departments in the universities. Finally, 60 participants $(14 \%)$ work as managers (deans, chairs, board members, etc.). This distribution of participants uniformly covered the various positions at both academic and non-academic departments in the universities.

The survey that we distributed to the 435 participants was constructed as follows: for each of the 100 KPIs, we generated one or more questions that we designed such that we can deduce the weight (or impact) of the KPI from the answer(s). Some of these questions were grouped together into sections. Others were standalone questions that constituted the last section of the survey. The survey contained a 
total of eight sections. For example, the first section has the following title: "Please indicate whether you agree or disagree with each of these statements related to universities in Lebanon". One of the statements in this section is: "The university must organize entrance exams". Another statement is: "The university should collaborate with industries and business experts when defining the content of courses". For each statement, the participant is required to indicate whether he/she strongly agrees, agrees, disagrees, strongly disagrees, or doesn't have an opinion on the statement. Other sections ask the participants to give a rating between 1 and 5 to each statement in the section. For example, the title of section 2 is: "On a scale between 1 and 5, to what extent you believe each of these factors is important to the overall quality of a university in Lebanon? (where 1 = least important, 5 = most important)". Examples of factors mentioned in this section are: "The university should have and maintain a professional website that can be used by its faculty, staff, students, and visitors to obtain various services and information" and "The university should compare its achieved and target quality levels with those defined in the Lebanese MEHE standards and by competitors". The last section in the survey contained open questions in which the participant can select one out of three choices as the answer of a certain question, or he/she can write the answer that he/she thinks is most correct. For example, one of the questions of this section is: "Should a Lebanese university suggest several possible educational tools and software, and allow each instructor to select the tools that are most suitable to his/her courses?" The choices that a participant can select as an answer to this question are:

a) Yes. Each instructor should select all tools and technologies that he/she wants to use in his/her courses and the university should provide these tools and technologies

b) Yes. The technology committee in the university should provide a list of all technologies (software and hardware) that the university can acquire, and allow instructors to select

c) No. The university curriculum committee should select the suitable technologies for each course

d) Other, please specify:

If the participant selects the last choice, he/she has an empty space to write his/ her answer. The complete survey is attached as a supplementary file to this paper.

For each KPI, we defined a method to deduce its corresponding weight (out of 10) from the question or questions that are related to the KPI. For example, the statement "The university must organize entrance exams" in the first section is related to KPI52. If the participant selects strongly agree, agree, disagree, or strongly disagree as an answer to this statement, then the weight of KPI52 is set to 10, 8, 4, 2 respectively (by this participant). Weights of other KPIs can be deduced directly from the rating (between 1 and 5) of the corresponding statement in sections that require the participant to specify a rating for each statement (note that the rating is multiplied by 2 to obtain the KPI weight). The most difficult weights to calculate were those of KPIs that were related to open questions in the last section of the survey. For those, we needed to read the answer of the participant and deduce the most correct weight from it. After we deduced the weight of each KPI for each participant, we calculated the average weight of each KPI by summing the weights of this KPI given by all participants and dividing the result by the number of participants. Table 1 shows the final weights of the $100 \mathrm{KPIs}$, where each weight in Table 1 is the average of the 435 weights given by the participants. In the next section, we discuss the obtained average values for the weights and the factors that affected the participants' answers.

Before we can use the weights in our model, we need to normalize them. This was done as follows: first, we add the 100 weights in Table 1 to obtain $\sum_{i=1}^{100}($ weight $)$. Then we calculate the normalized value of each weight by using the following equation:

$$
N W_{j}(\text { normalized weight } j)=\frac{\text { weight }_{j} * 100}{\sum_{i=1}^{100}\left(\text { weight }_{i}\right)}
$$


where weight $t_{j}$ is the original weight of $K P I_{j}$ and $N W_{j}$ is the normalized weight of the same KPI. Note that we multiply the weight by 100 which is the number of KPIs before dividing it by the sum of the weights of all KPIs in order to obtain the normalized weight. Table 2 shows the normalized weights of the 100 KPIs. On the other hand, Tables 3 and 4 show some statistics related to the weights. Table 3 helps us understand where most weights were concentrated. Note that the minimum and maximum obtained weights were 2.06 and 9.64 (over 10). This range was divided into the following intervals: [2.06, 2.5], [2.5, $3.0],[3.0,3.5],[3.5,4.0] \ldots[9.0,9.5],[9.5,9.64]$. For each of the resulting 16 intervals, we calculated the number of weights that lied within the interval. The results are shown in Table 3.

We notice from Table 3 that the major concentration of weights is between 6.5 and 9.5. The percentage of KPIs that were given a weight less than 6.5 or greater than 9.5 is $21 \%$, while the percentage of KPIs whose weight is between 6.5 and 9.5 is $79 \%$. In general, if we classify the KPIs according to their importance to the model as least important (weight $<3$ ), slightly important $(3<$ weight $<6$ ), important $(6$ $<$ weight $<8)$, very important $(8<$ weight $<9)$, and extremely important (weight $>9)$, then the percentage of weights for each of these five groups are $4 \%, 13 \%, 28 \%, 35 \%$, and $20 \%$. Hence, we notice that $83 \%$ of the weights were considered important, very important, or extremely important by the participants, while only $17 \%$ were considered slightly or less important for reasons that we will discuss in the next section.

\begin{tabular}{|c|r|r|r|r|r|r|r|}
\hline KPI \# & Weight & \multicolumn{1}{|c|}{ KPI \# } & Weight & \multicolumn{1}{|c|}{ KPI \# } & Weight & \multicolumn{1}{|l}{ KPI \# } & \multicolumn{1}{c|}{ Weight } \\
\hline 1 & 8.21 & 26 & 7.80 & 51 & 8.24 & 76 & 9.09 \\
\hline 2 & 8.62 & 27 & 7.17 & 52 & 8.24 & 77 & 9.08 \\
\hline 3 & 6.06 & 28 & 5.22 & 53 & 7.69 & 78 & 9.18 \\
\hline 4 & 9.13 & 29 & 9.06 & 54 & 3.52 & 79 & 8.85 \\
\hline 5 & 9.47 & 30 & 8.31 & 55 & 3.47 & 80 & 9.28 \\
\hline 6 & 8.39 & 31 & 8.23 & 56 & 3.84 & 81 & 9.18 \\
\hline 7 & 8.69 & 32 & 8.29 & 57 & 8.36 & 82 & 9.31 \\
\hline 8 & 7.74 & 33 & 8.53 & 58 & 6.22 & 83 & 9.03 \\
\hline 9 & 7.38 & 34 & 8.78 & 59 & 7.30 & 84 & 8.47 \\
\hline 10 & 6.55 & 35 & 4.70 & 60 & 8.83 & 85 & 9.36 \\
\hline 11 & 6.83 & 36 & 8.92 & 61 & 2.91 & 86 & 7.75 \\
\hline 12 & 7.90 & 37 & 4.52 & 62 & 2.75 & 87 & 8.37 \\
\hline 13 & 6.94 & 38 & 8.95 & 63 & 2.06 & 88 & 7.85 \\
\hline 14 & 5.63 & 39 & 4.82 & 64 & 8.72 & 89 & 8.45 \\
\hline 15 & 7.11 & 40 & 7.70 & 65 & 8.87 & 90 & 8.59 \\
\hline 16 & 7.47 & 41 & 4.28 & 66 & 9.13 & 91 & 9.08 \\
\hline 17 & 8.25 & 42 & 6.75 & 67 & 8.55 & 92 & 9.21 \\
\hline 18 & 9.25 & 43 & 7.64 & 68 & 8.70 & 93 & 8.57 \\
\hline 19 & 8.66 & 44 & 8.06 & 69 & 2.94 & 94 & 9.43 \\
\hline 20 & 7.83 & 45 & 3.97 & 70 & 8.82 & 95 & 6.69 \\
\hline 21 & 6.10 & 46 & 7.43 & 71 & 7.98 & 96 & 9.48 \\
\hline 22 & 8.64 & 47 & 6.51 & 72 & 8.87 & 97 & 7.63 \\
\hline 23 & 7.70 & 48 & 4.80 & 73 & 9.39 & 98 & 9.15 \\
\hline 24 & 8.23 & 49 & 3.64 & 74 & 9.64 & 99 & 8.62 \\
\hline 25 & 5.95 & 50 & 6.83 & 75 & 8.23 & 100 & 8.09 \\
\hline
\end{tabular}

Table 1. Average weights for the 100 KPIs in the Technology Integration Model

Table 4 shows the maximum, minimum, average, median, skew, range, and standard deviation of the obtained weights, both original and normalized values. We notice that the weight distribution has an average value of 7.5 , a median equal to 8.2 , and a skew equal to -1.3 ; which reflects that the distribution is 
bunched up towards the high values. The range of all weights is 7.58 , and the standard deviation is 1.82 , which indicates that the weights average variability around the mean is within the range $[5.73,9.37]$, which is expected since most of the weights are within this range as Table 3 shows. Finally, if we calculate the Coefficient of Variation $(\mathrm{CV})$, we find it equal to $(1.82 / 7.55)=0.24$, which indicates that the majority of the weights are clustered around the mean with small variability. These statistics indicate that the participants considered most of the KPIs as important to the TIP. In the next section, we discuss the reasons behind the participants' answers.

\begin{tabular}{|c|r|r|r|r|r|r|r|}
\hline KPI \# & Weight & \multicolumn{1}{|c|}{ KPI \# } & Weight & \multicolumn{1}{|c|}{ KPI \# } & \multicolumn{1}{l|}{ Weight } & \multicolumn{1}{c|}{ KPI \# } & \multicolumn{1}{c|}{ Weight } \\
\hline 1 & 1.09 & 26 & 1.03 & 51 & 1.09 & 76 & 1.20 \\
\hline 2 & 1.14 & 27 & 0.95 & 52 & 1.09 & 77 & 1.20 \\
\hline 3 & 0.80 & 28 & 0.69 & 53 & 1.02 & 78 & 1.22 \\
\hline 4 & 1.21 & 29 & 1.20 & 54 & 0.47 & 79 & 1.17 \\
\hline 5 & 1.25 & 30 & 1.10 & 55 & 0.46 & 80 & 1.23 \\
\hline 6 & 1.11 & 31 & 1.09 & 56 & 0.51 & 81 & 1.22 \\
\hline 7 & 1.15 & 32 & 1.10 & 57 & 1.11 & 82 & 1.23 \\
\hline 8 & 1.03 & 33 & 1.13 & 58 & 0.82 & 83 & 1.20 \\
\hline 9 & 0.98 & 34 & 1.16 & 59 & 0.97 & 84 & 1.12 \\
\hline 10 & 0.87 & 35 & 0.62 & 60 & 1.17 & 85 & 1.24 \\
\hline 11 & 0.91 & 36 & 1.18 & 61 & 0.39 & 86 & 1.03 \\
\hline 12 & 1.05 & 37 & 0.60 & 62 & 0.36 & 87 & 1.11 \\
\hline 13 & 0.92 & 38 & 1.19 & 63 & 0.27 & 88 & 1.04 \\
\hline 14 & 0.75 & 39 & 0.64 & 64 & 1.16 & 89 & 1.12 \\
\hline 15 & 0.94 & 40 & 1.02 & 65 & 1.18 & 90 & 1.14 \\
\hline 16 & 0.99 & 41 & 0.57 & 66 & 1.21 & 91 & 1.20 \\
\hline 17 & 1.09 & 42 & 0.89 & 67 & 1.13 & 92 & 1.22 \\
\hline 18 & 1.23 & 43 & 1.01 & 68 & 1.15 & 93 & 1.14 \\
\hline 19 & 1.15 & 44 & 1.07 & 69 & 0.39 & 94 & 1.25 \\
\hline 20 & 1.04 & 45 & 0.53 & 70 & 1.17 & 95 & 0.89 \\
\hline 21 & 0.81 & 46 & 0.98 & 71 & 1.06 & 96 & 1.26 \\
\hline 22 & 1.14 & 47 & 0.86 & 72 & 1.18 & 97 & 1.01 \\
\hline 23 & 1.02 & 48 & 0.64 & 73 & 1.24 & 98 & 1.21 \\
\hline 24 & 1.09 & 49 & 0.48 & 74 & 1.28 & 99 & 1.14 \\
\hline 25 & 0.79 & 50 & 0.91 & 75 & 1.09 & 100 & 1.07 \\
\hline
\end{tabular}

Table 2. Normalized weights for the 100 KPIs in the Technology Integration Model

\begin{tabular}{|c|c|c|c|}
\hline Weight Range (Normalized) & Number of KPIs & Weight Range (Normalized) & Number of KPIs \\
\hline $2.06-2.5(0.27-0.33)$ & 1 & $6.0-6.5(0.80-0.86)$ & 3 \\
\hline $2.5-3.0(0.33-0.40)$ & 3 & $6.5-7.0(0.86-0.93)$ & 7 \\
\hline $3.0-3.5(0.40-0.46)$ & 1 & $7.0-7.5(0.93-0.99)$ & 6 \\
\hline $3.5-4.0(0.46-0.53)$ & 4 & $7.5-8.0(0.99-1.06)$ & 12 \\
\hline $4.0-4.5(0.53-0.60)$ & 1 & $8.0-8.5(1.06-1.13)$ & 19 \\
\hline $4.5-5.0(0.60-0.66)$ & 4 & $8.5-9.0(1.13-1.19)$ & 19 \\
\hline $5.0-5.5(0.66-0.73)$ & 1 & $9.0-9.5(1.19-1.26)$ & 1 \\
\hline $5.5-6.0(0.73-0.80)$ & 2 & $9.5-9.64(1.26-1.28)$ & \\
\hline
\end{tabular}

Table 3. Number of KPIs in each of the 16 selected ranges 


\begin{tabular}{|c|c|c|}
\hline Parameter & Value & Normalized \\
\hline Minimum & 2.06 & 0.27 \\
\hline Maximum & 9.64 & 1.28 \\
\hline Average (Mean) & 7.55 & 1.00 \\
\hline Median & 8.23 & 1.09 \\
\hline Skew & -1.33 & -1.33 \\
\hline Range & 7.58 & 1.00 \\
\hline Standard Deviation & 1.82 & 0.24 \\
\hline
\end{tabular}

Table 4. Statistics related to the weights of the 100 KPIs

\section{Discussion}

After we collected the survey answers from the participants, we generated the weights and statistics that were presented in the previous section; then we made interviews with most of the participants (about $87 \%$ of them) asking each one about the reasons behind his/her answers. We focused on asking about KPIs that were given by the participant very low or very high weights, and on KPIs that were given a weight that deviated considerably from the average weight. We collected the answers to our interviews and analyzed them. We present in this section a discussion of the important and common issues that were mentioned by the participants, illustrating the factors that were considered by participants when answering the survey questions, which led to the corresponding weights of some of the KPIs.

KPI ${ }_{3}$ : The participants believed that although the fact that an "HEI takes into account students' feedback and recommendations regarding the curriculum content" is very important to the quality of the HEI, it doesn't play an important role in the TIP.

$\mathbf{K P I}_{10}$ and KPI $\mathbf{I}_{11}$ : The participants believed that these KPIs are important for the HEI, but are not much related to the TIP. They said that instructors should know very well their roles and the connection between their courses and other courses in the major. However, these factors do not significantly improve or worsen the process of adopting and implementing new technologies.

$\mathbf{K P I}_{13}$ : Many participants believed that when students learn Interdisciplinary studies and activities, it will enable them to improve their skills with new technologies which will ease and strengthen the TIP. However, other participants gave this KPI a low weight since they didn't agree much with the previous statement, which resulted in a medium weight for this KPI.

KPI $_{14}$ : Most participants stated that the process of students' participation in "in quality-related committees and councils" has a small impact on the TIP.

$\mathbf{K P I}_{15}$ and $\mathbf{K P I}_{16}$ : Most participants stated that selecting the correct type of assessment is very important for the success of the course, but is not essential for a successful TIP. Rather, the objective of the assessment is important, as it defines the correct technology that is suitable for the course (this resulted in higher weight for $\mathrm{KPI}_{17}$ ).

$\mathbf{K P I}_{18}$ : All participants agreed that using "technology-based assessment techniques, such as e-portfolios" is one of the key factors related to the TIP. Many participants stated that using assessment methods that utilize modern technology tools is very important to the improvement of the university.

$\mathbf{K P I}_{21}$ : The participants agreed that "the teaching abilities and the practical skills" of an instructor are very important in "determining the instructor's rank". However, this factor does not relate much to the TIP.

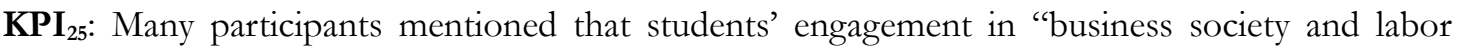
market" is very important for the quality of the university and its graduates. But it doesn't affect much the process of choosing and implementing correct technologies within the university. 
$\mathbf{K P I}_{28}$ : The participants stated that defining and monitoring the "outside-classroom interactions between students and instructors" is not much related to what type of technologies should be used in various services offered by the university.

$\mathbf{K P I}_{35}$ : The process of "tracking students after graduation" was considered by the participants to have minor or no effect on the TIP. Many participants stated that although this process plays an important role in defining which qualities are weak or missing in the graduating students, it does not imply which technologies are correctly or incorrectly used at the university.

$\mathbf{K P I}_{37}$ : Participants noted that providing internships at high-quality institutions is important for students and the overall quality of the university, but is not related much to the TIP. Few participants stated that they find this factor important since students will help the university with technology-related skills they learn from their internships.

$\mathbf{K P I}_{39}$ : The process of distributing the "credit load efficiently for each major" was considered by the participants to have "very little effect" or "not related at all" to the TIP.

KPI $\mathbf{I}_{41}$ : Most of the participants considered that there is no relation between the salary of part and full-time instructors and the TIP. Other participants considered that a proper salary will benefit the TIP by giving instructors incentives to put a good effort in selecting and integrating new technologies.

$\mathbf{K P I}_{42}$ : Some of the participants considered that selecting a proper number of part and full-time instructors and hence a proper number of students per section are important for a successful TIP, as using new technology in a correct way requires a limit on the number of students per class. Others did not share this opinion and put a small weight for this KPI.

KPI $_{45}$ : Most participants considered defining a "maximum allowed number of semesters for each degree" not related to the TIP from any aspect.

$\mathbf{K P I}_{47}$ : Some participants said that when the university has a goal of "offering transferrable credits", it tries more to adopt new technologies in a successful manner. Others considered this KPI not related to the TIP.

$\mathbf{K P I}_{48}$ and $\mathbf{K P I}_{49}$ : Almost all participants commented that the existence or nonexistence of a "variety of degrees" and "multidisciplinary programs" does not have much influence on the TIP.

$\mathbf{K P I}_{50}$ : Many participants believed that when the university "offers postgraduate programs", it gains important experience that helps in implementing a successful TIP. Others considered that this factor has little impact on the TIP.

$\mathbf{K P I}_{51}$ and $\mathbf{K P I}_{52}$ : Most participants stated that when the university has proper admission strategy, application screening, and entrance exams, it gets a precise insight about the technology-related requirements of accepted students. This will help the university in designing a correct TIP.

$\mathbf{K P I}_{54}$ and $\mathbf{K P I}_{55}$ : The financial issues such as education fees, financial aid, and scholarships were not considered a factor that is related to the TIP.

KPI $_{56}$ : The participants considered career advising as a service that benefits the reputation and graduates, but does not affect and is not related to the type and quality of technologies adopted by the university.

KPI $_{58}$ : Some participants considered that this KPI is not much related to the TIP. However, many participants stated that one of the factors that will cause the promoting of a successful faculty member is her/his successful utilization of new technologies, which promotes other instructors to learn and improve in this area. 
$\mathbf{K P I}_{61}, \mathbf{K P I}_{62}$, and $\mathbf{K P I}_{63}$ : The participants considered that it is important for the university to exploit modern technology tools in providing the best medical care, safety and security, and sports and social services for its employees and students; however, the existence or nonexistence of these services doesn't impact the process of successful technology integration.

KPI $_{65}$ and KPI 6 : All participants agreed that the process of defining and monitoring correct decision making within the university plays a very important role not only on the TIP but on the overall development of the university.

KPI $_{68}$ : Participants noted that it is essential to define a list of qualities to be achieved using modern technology tools and to follows a precise plan for achieving these qualities. Almost all participants agreed that this factor is the basis of a successful TIP.

KPI $_{69}$ : The participants argued that this KPI is not applicable in the Lebanese HEIs, as the Lebanese Ministry of Higher Education (MEHE) does not define any standards for the TIP. The participants noted that this issue is very important in Lebanon, and urged for future efforts by the MEHE to define standards for technology selection and integration in the various sectors of the Lebanese higher education.

$\mathbf{K P I}_{71}$ : The participants commented that although the aspect of being "environmental preservative" is not directly related to the TIP; it remains very important for achieving a successful TIP. Most of the participants said that a TIP that does not include considerations for environment protection will fail eventually.

$\mathbf{K P I}_{73}$ and $\mathbf{K P I}_{74}$ : Almost all participants gave these KPIs a weight of 9 or 10 . They stated that it is most essential for the TIP to have a professional dedicated department for educational technology-related matters and technology selection and implementation research and testing.

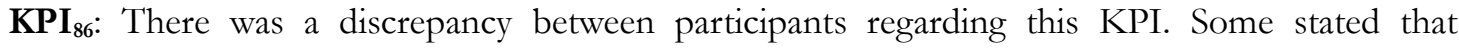
utilizing technology tools to help students adjust their schedules is very important. Others saw it less important saying that most Lebanese students do not have schedule obligations and that most Lebanese universities demand commitment from the students regarding their attendance and learning times requirements. Hence, we received high, average, and low weights for this KPI, resulting in an average weight equal to 7.75 .

KPI $_{88}$ : Many participants said that "integrating blended and mobile learning in the curricula" is very important for the future development of the Lebanese higher education system. For the current time, other technology-related issues, such as improving the instructors' and administrators' technology-related skills and visions; and utilizing technology to improve the basic infrastructure and services of Lebanese universities, should be considered before we can focus on integrating blended and mobile learning techniques.

$\mathbf{K P I}_{89}$ and $\mathbf{K P I}_{90}$ : The idea of utilizing technology enhancements to improve the learning opportunities for students with disabilities was faced by great enthusiasm by many participants, who gave high weights for these KPIs.

$\mathbf{K P I}_{94}$ : Most participants agreed that this KPI is among the most important for the TIP. They emphasized the fact that the Lebanese higher education system is still using excessively traditional assessment methods, while important technology-based assessment techniques are not considered or even not known to many universities. The participants consider this KPI as one of the main factors that will help in the development of the higher education sector in Lebanon.

KPI $_{95}$ : The participants had different opinions related to this KPI. Some said that making use of technology enhancements to reduce educational costs is a main factor in the development of a Lebanese HEI. Others stated that the educational fees should be based on the quality of the 
services offered by the university, and that a Lebanese university that offers much better services than other universities cannot demand the same low educational costs as the costs demanded by these universities that are affordable by most of the Lebanese society.

\section{Conclusion and Future Work}

Having generated the weights for the KPIs that constitute our proposed Technology Integration Model, we finally discuss how we can apply this model to a Lebanese university and what the implications of applying the model are. In general, our proposed model will enable a Lebanese HEI to have a clear insight about the effectiveness of the technologies that it implements and uses, and whether it is adopting and using these technologies correctly. In addition, our model will help a Lebanese university define the areas in which it should develop by adopting new technologies, and what technologies should be best chosen for these areas. With respect to the first point, the HEI should selflessly calculate its own score for each of the 100 KPIs (between 0 and 10). Next, the HEI should multiply the score of the KPI with the KPI's normalized weight to get the normalized score of each KPI. Finally, the normalized scores for all KPIs are added to obtain the HEI total score (over 100), which reflects the effectiveness and correctness of the technology integration process within the HEI. With respect to the second point, the HEI can select the KPIs on which it achieved a low score. Next, the HEI can order these KPIs according to their weights and/or according to the HEI own interests (i.e., which areas it wishes to focus on developing first). Finally, the HEI should search for strategies and solutions to increase its score of these KPIs, which will enhance its overall performance in the Technology Integration Model.

Our next step in this research project will be studying the implementation of our proposed TIM within selected universities in Lebanon. First, we need to define, for each KPI, the methods that should be used to calculate the HEI score for the KPI. For example, for KPI1, the score is calculated by asking the curriculum committees in the HEI about the methods they use to define the learning outcomes (LOs). Based on the answers, we can deduce the level of standardization and the professionalism used by the HEI in general to define the courses' LOs, from which we define the HEI score for KPI1. Other KPIs could require interviews with instructors, students, business companies and institutions who hire the HEI graduates, etc. We will also need to review the detailed curricula documentations, the internal regulations and policies, and the data stored by the university, after obtaining clearance from the corresponding administrators, to calculate the scores of other KPIs (such as KPI14, KPI17, KPI28, KPIs 41 to 45, KPIs 51 to 53, KPI57, KPIs 65 and 66, etc.). In addition, we will need to attend sample lectures and laboratories that will help us in calculating the scores of some KPIs (such as KPI9, KPIs 11 to 13, KPI19, and KPI80).

We expect that the process of defining the methods for calculating the score for each KPI will be a complex and lengthy one. After that, we need to apply this process for each of the eight universities that we stated in Section 4, in order to calculate the score of each KPI and the total score for each university. This will enable us to rank these universities according to the proposed TIM and to define the areas in which each university needs to improve. Finally, by analyzing the overall results and selecting KPIs with common low scores, we aim to deduce the areas in which the Lebanese higher education sector needs to enhance from the perspective of technology selection and implementation. We have already begun defining the method(s) to calculate the score for each KPI. We aim at finishing the described tasks by the end of 2019 .

\section{Declaration of Conflicting Interests}

The authors declared no potential conflicts of interest with respect to the research, authorship, and/or publication of this article.

\section{Funding}

The authors received no financial support for the research, authorship, and/or publication of this article. 


\section{References}

Al-Alwani, A. (2014). Information technology integration in higher education: A novel approach for impact assessment. International Journal of Emerging Technologies in Learning (iJET), 9(6), 32-36. https://doi.org/10.3991/ijet.v9i6.4036

Kaissi, B., Abou-Chahine, S., \& Jammal, A. (2009, March). Towards a new higher education quality assurance system for Lebanon. In 9th biennial INQAAHE Conference. Abu Dhabi, UAE.

EACEA (Education, Audiovisual and Culture Executive Agency) (2017). Overview of the Higher Education System. Available at: https://eacea.ec.europa.eu/sites/eacea-site/files/countryfiches_lebanon_2017.pdf

Ghalayini, N., \& El-Ghali, H.A. (2016). Why Doesn't Lebanon Have a National Quality Assurance Agency for Higher Education Yet? Education and Youth Policy Research.

Sphere (Support and Promotion for Higher Education Reform Experts) (2017). Higher education in Lebanon. Available at: $\underline{\text { http://supporthere.org/page/higher-education-lebanon }}$

Published by OmniaScience (www.omniascience.com)

Journal of Technology and Science Education, 2019 (www.jotse.org)

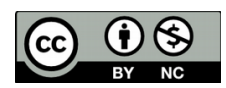

Article's contents are provided on an Attribution-Non Commercial 4.0 Creative commons International License. Readers are allowed to copy, distribute and communicate article's contents, provided the author's and JOTSE journal's names are included. It must not be used for commercial purposes. To see the complete licence contents, please visit https://creativecommons.org/licenses/by-nc/4.0/. 